\title{
Proteasome Inhibitor or Immunomodulators Which is The Optimal Maintenance For Newly Diagnosed Multiple Myeloma: A 7-Year Real-World Data in China.
}

\section{Xiaoyan Han}

Zhejiang University School of Medicine First Affiliated Hospital

\section{Chunxiang Jin}

Zhejiang University School of Medicine First Affiliated Hospital

\section{Gaofeng Zheng}

Zhejiang University School of Medicine First Affiliated Hospital

\section{Donghua He}

Zhejiang University School of Medicine First Affiliated Hospital

\section{Yi Zhao}

Zhejiang University School of Medicine First Affiliated Hospital

Yi Li

Zhejiang University School of Medicine First Affiliated Hospital

\section{Wenjun Wu}

Zhejiang University School of Medicine First Affiliated Hospital

\section{Weiyan Zheng}

Zhejiang University School of Medicine First Affiliated Hospital

\section{Guoqing Wei}

Zhejiang University School of Medicine First Affiliated Hospital

\section{Enfan Zhang}

Zhejiang University School of Medicine First Affiliated Hospital

\section{Huang He}

Zhejiang University School of Medicine First Affiliated Hospital Jingsong $\mathrm{He}$

Zhejiang University School of Medicine First Affiliated Hospital Zhen Cai ( $\boldsymbol{D}$ caiz@zju.edu.cn )

Zhejiang University School of Medicine First Affiliated Hospital https://orcid.org/0000-0001-6026-3804

\section{Primary research}


Keywords: Maintenance, proteasome inhibitor, immunomodulators, subgroup analysis, optimal maintenance duration

Posted Date: February 19th, 2021

DOI: https://doi.org/10.21203/rs.3.rs-205639/v1

License: (c) (1) This work is licensed under a Creative Commons Attribution 4.0 International License. Read Full License 


\section{Abstract}

Background: According to different patients' subgroups choose optimal maintenance therapy.

Methods: 226 Newly Diagnosed Multiple Myeloma (NDMM) patients in our center were included, the patients' characteristics, survival, response, subgroup analysis, adverse reactions were compared between the patients with or without maintenance, proteasome inhibitor $(\mathrm{PI})$ or immunomodulators (IMiDs) maintenance. And the survival of different maintenance duration of bortezomib-based regimens was also analyzed.

Results: The maintenance therapy not only upgraded more patients' response (34.3 vs. $13.3 \%, p=0.006)$, but also significantly prolonged the patients' PFS (median PFS: 41.1 vs. 10.5 months, $p<0.001$ ) and OS (median OS: not reached vs. 38.6 months, $\mathrm{p}<0.001$ ). Compared with IMiDs, the PFS (median PFS: 43.7 vs. 38.5 months, $p=0.034$ ) and OS (median OS: not reached vs. 78.5 months, $p=0.041$ ) can both benefit from bortezomib-based maintenance. The patients younger than 65 years old with bortezomib-based maintenance significantly prolonged the $O S(p=0.032)$. Patients achieving the only partial response (PR) after induction and consolidation therapy experienced a significantly longer PFS and OS with bortezomibbased maintenance compared to IMiDs $(p=0.007,0.002)$. Besides, the high-risk patients (ISS 2-3, DS 2-3 and RISS 2-3) with bortezomib-based maintenance can benefit PFS ( $p=0.002,0.02,0.06$, respectively) and OS ( $p=0.059,0.047,0.044$, respectively) compared with IMiDs. The OS was significantly prolonged in the patients who received $\geq 12$ months of bortezomib-based maintenance than those with maintenance < 12 months $(p<0.001)$, but no difference was observed in OS between the patients who received the 12-24 or $\geq 24$ months of bortezomib-based maintenance $(p=0.292)$.

Conclusion: Maintenance therapy can significantly improve the survival of NDMM patients. Bortezomibbased regimens maintenance was more superior to IMiDs in overall PFS and OS. The beneficial effect is most evident in patients achieving the only PR after induction and consolidation therapy, and the highrisk patients. Moreover, younger patients also could benefit from bortezomib-based maintenance in OS. The bortezomib-based maintenance duration lasting 12-24 months after induction and consolidation therapy can reach a satisfactory OS.

\section{Background}

Multiple myeloma (MM), a clonal plasma cell neoplasm characterized by monoclonal immunoglobulin production, the second most common hematologic malignancies accounts for about $1-2 \%$ of all cancers[1]. In the past two decades, despite autologous stem cell transplantation and novel agents have significantly improved the outcome of MM patients, however, most patients experience disease progression or relapse inevitably, maintenance treatment has become a necessary means to deepen the depth of response and sustain the deep response, as well as survival improvement[2, 3]. The bortezomibbased regimens are widely used in induction therapy [4-6]. Yet its experience in maintenance therapy is still limited. Therefore, we summarized the 7-year follow-up data of MM patients in our center, compared 
the proteasome inhibitor $(\mathrm{PI})$ bortezomib-based regimens with the immunomodulators (IMiDs) thalidomide and lenalidomide in maintenance treatment to clarify their role in the upgrade of response depth, survival improvement, and evaluate its adverse reactions. By subgroup analysis trying to illuminate the most appropriate maintenance therapy approach for corresponding patient subgroups.

\section{Materials And Methods}

\section{Patients}

Newly diagnosed multiple myeloma(NDMM) patients who had achieved at least a partial response (PR) after induction and consolidation therapy of bortezomib based regimens at the First Affiliated Hospital of Zhejiang University Medical College from May 23, 2013, to December 13, 2018, were evaluated for inclusion in our retrospective study. All patients were followed up for mortality and survival to October 1 , 2020. Demographic and disease characteristics and treatment regimens were extracted from electronic medical records under the approval of review boards. Patients were stratified according to Durie Salmon (DS) stage, International Staging System (ISS) disease stage, and revised-ISS (R-ISS) stage at diagnosis. Due to lack of FISH data, 20 patients of the maintenance group (including 15 patients in the PI subgroup, 5 patients in the IMiDs subgroup) and 2 patients of the no maintenance group can't be stratified by RISS staging.

\section{Treatment Regimens}

All patients received bortezomib-based regimens as induction therapy, including PD regimen (bortezomib and dexamethasone), PCD regimen (bortezomib, cyclophosphamide, dexamethasone), PAD regimen (bortezomib, doxorubicin, dexamethasone), PTD (bortezomib, thalidomide, dexamethasone), and VRD (bortezomib, lenalidomide, dexamethasone). All patients received subcutaneous bortezomib $1.3 \mathrm{mg} / \mathrm{m}^{2}$, young patients ( $<65$ years old) received a 28 days-course-treatment on day $1,4,8,11$. Old patients ( $\geq 65$ years old) received a 35 days-course-treatment on day $1,8,15,22$. Dexamethasone was given following bortezomib on day $1-2,4-5,8-9$, and $11-12$ (or day $1-2,8-9,15-16,22-23$ ) with $20 \mathrm{mg} /$ day intravenously. Similarly, Doxorubicin $\left(10 \mathrm{mg} / \mathrm{m}^{2}\right)$ and cyclophosphamide $\left(200 \mathrm{mg} / \mathrm{m}^{2}\right)$ were given intravenously on day $1,4,8,11$ (or day $1,8,15,22)$. Thalidomide (100mg/day) and lenalidomide (10 $25 \mathrm{mg} /$ day) was given orally during the entire treatment cycle.

After 3 to 4 cycles of induction therapy, autologous hematopoietic stem cell transplantation (ASCT) was implemented on some patients eligible for transplantation, according to the patient's age, general state, and patient's willingness. Other patients not eligible for transplantation continued to receive 2 to 4 courses of consolidation therapy which are basically as same as the induction regimens.

After 3 to 4 cycles of induction and consolidation therapy with or without ASCT, the majority of patients received maintenance therapy. A large proportion of patients received proteasome inhibitor bortezomibbased regimens such as PD, PCD, PAD, PTD, VRD for maintenance, with a 3-month cycle, during maintenance all patients received bortezomib lasting 5 weeks on day $1,8,15,22$. The other part of 
patients adopted immunomodulators such as T (thalidomide), R (lenalidomide), TD (thalidomide and dexamethasone), RD (lenalidomide and dexamethasone) as maintenance.

\section{Efficacy and Safety Evaluation}

Outcome measures included the response to treatment, overall survival (OS), and progression-free survival (PFS). The response to treatment was defined as the International Myeloma Working Group uniform response criteria, including partial response (PR), very good partial response (VGPR), and complete response (CR)[7]. Adverse reaction assessment adopts the National Cancer Institute Common Toxicity Criteria for AEs, version 5.0.

\section{Statistical Analysis}

Statistical analysis was conducted by SPSS 21.0 software (SPSS, Chicago, IL). Baseline characteristics were assessed with descriptive statistical analysis: frequency distribution $(n, \%)$ presented for categorical variables and compared using the chi-squared test, median (range) are presented for continuous variables and compared using T-test. PFS and OS analyses were performed using the Kaplan-Meier method, and the log-rank test was used to analyze the differences between survival curves. A value of $p<$ 0.05 indicated statistical significance, and all tests were two-sided.

\section{Results}

\section{Maintenance vs. no maintenance}

\section{Patient Characteristics}

The clinical data and biological characteristics of 181 patients with maintenance and 45 patients without maintenance were summarized in Table 1. Significant differences can be observed in ASCT. The proportion of patients who adopted ASCT was higher in the maintenance group (17.1 vs. 2.3\%). Other baseline characteristics were basically balanced.

\section{Survival}

The median follow-up duration for all patients was $36.9 \llbracket 3.6-86.0 \rrbracket$ months $\rrbracket$

the median PFS was 41.1 (95\% Cl: 34.5-47.7) months for the patients who received maintenance treatments, and 10.5 (95\% Cl: 8.0-13.1) months for the no maintenance group $(p<0.001)$ (Figure 1A). The median OS of the arm adopted maintenance was not reached, the median OS of the patients who without maintenance was 38.6 (95\% Cl: 27.0-50.2) months, the survival was distinctly prolonged for patients who adopted maintenance $(p<0.001)$ (Figure 1B).

\section{Response}


During maintenance, the upgrade of response from PR to at least VGPR was more common in the maintenance group ( 34.3 vs. $13.3 \%, p=0.006$ ). The best response after maintenance, the PR rate was $17.7 \%$, and at least VGPR rate was $82.3 \%$ in patients who received maintenance versus $42.9 \%$ and $57.8 \%$ in the no maintenance group $(p<0.001)$.

\section{Proteasome inhibitor vs. Immunomodulators}

\section{Patient Characteristics}

Baseline characteristics of 181 patients who received maintenance treatments, including 127 with $\mathrm{PI}$ and 54 with IMiDs, were presented in Table 2. No significant statistical difference was observed between the two groups of variables. The patients who received PI maintenance were slightly younger, with a median age of 62 years old compared to 63 years old in the IMiDs group. The proportion of patients using PD as the induction regimens was slightly higher in the PI group (16.5 vs. 7.4\%). The CR rate after induction and consolidation therapy was higher in the PI group (44.9 vs. 29.6\%). In the PI group, there are 7 (5.5\%) patients with PAD maintenance, 93 (73.2\%) patients with PCD maintenance, 21 (16.5\%) patients with PD maintenance, and 6 (4.8\%) patients with VRD maintenance. In the IMiDs group, there are $5(9.3 \%)$ patients with R maintenance, 28 (51.9\%) patients with RD maintenance, 19 (35.2\%) with T maintenance, and 2 (3.7\%) with TD maintenance.

\section{Survival}

The median follow-up of the total maintenance patients was 39.2 (3.6-86.0) months. During the followup, 62 patients (48.8\%) and 38 patients (70.4\%) had disease recurrence or progression in $\mathrm{PI}$ group and IMiDs group respectively, with a median PFS of 43.7 (95\% Cl: $30.3-57.1)$ months versus 38.5 (95\% Cl: 19.1 - 58.0) months ( $p=0.034$ ) (Figure 2A). As for the overall survival, 21 patients (16.5\%) and 17 patients (31.5\%) died during the follow-up, with a median OS not reached in the PI group versus 78.5 (50.1 - 106.9) months in the IMiDs group ( $p=0.041)$ (Figure 2B).

\section{Subgroup Analysis}

\subsection{Age and Creatinine}

For patients younger than 65 years, maintenance with PI significantly prolonged the $0 S(p=0.032)$, with a 5 -year OS of 81.5 versus $66.1 \%$, respectively. No statistical difference was observed in PFS between the two groups, with a 3-year PFS of 56.6 versus 55\%. As for patients aged 65 years and older, there was no significant difference in neither PFS nor OS between the two groups. For renal function, OS benefit was observed in the PI group in patients with baseline serum creatinine $<2 \mathrm{mg} / \mathrm{dl}$, with a 5-year OS of 76.8 vs. $64.9 \%(p=0.036)$. In those patients with normal renal function, PI maintenance therapy also improved the PFS compared with the IMiDs group, with a 3-year PFS of 58.4 vs. $52.0 \%(p=0.07)$, although the statistical difference was not significant. In the patients whose baseline serum creatinine $\geq 2 \mathrm{mg} / \mathrm{dl}$, there was no difference in PFS and OS between the two maintenance treatment options (Table 3). 


\subsection{Response after induction and consolidation therapy}

Patients achieving the only PR after induction and consolidation therapy experienced a significantly longer PFS and OS with PI maintenance compared with IMiDs, with 3-year-PFS of 44.8 and $25.0 \%$ ( $p=$ $0.007), 5$-year-OS of 77.9 and $45.1 \%(p=0.002)$. However, in the patients achieving at least VGPR, no difference was observed between the two groups in PFS or OS (Table 3 ).

\subsection{Clinical Stages}

Patients were stratified according to clinical stages. Patients in ISS 1, DS 1, and RISS 1 were classified as non-high risk; the other patients in ISS 2-3, DS 2-3, and RISS 2-3 were classified as high risk. Overall, highrisk patients receiving PI maintenance therapy can improve survival. The 3-year PFS of high-risk patients with PI or IMiDs maintenance was 57.0 vs. $40.3 \%, 56.5$ vs. $49.5 \%, 52.4$ vs. $48.6 \%$, respectively ( $p=0.002$, $0.02,0.06)$. The 5 -year OS of high-risk patients with PI or IMiDs maintenance was 71.4 vs. $55.2 \%, 73.9$ vs. $62.9 \%, 75.6$ vs. $62.6 \%$, respectively $(\mathrm{p}=0.059,0.047,0.044)$. In non-high-risk patients, no difference was observed in PFS or OS between two maintenance therapy options (Table 3).

\section{Adverse Reactions}

During maintenance treatment, the incidence of second primary malignancies was higher in the IMiDs group (0 vs. 3.7\%, $p=0.029)$. There were no significant statistical differences in other adverse reactions between the two maintenance treatment options. The most common hematological adverse events are thrombocytopenia (5.5 vs. $7.5 \%$ ) and Neutropenia (4.7 vs. 3.7\%). For non-hematological adverse events, the most frequent were peripheral neuropathy $(23.0 \mathrm{vs}$. $33.3 \%)$ and infection $(22.0 \mathrm{vs}$. $25.9 \%)$. The results were presented in Table 4.

\section{Treatment Duration of Proteasome Inhibitor Maintenance}

Proteasome Inhibitor bortezomib-based regimens are the main maintenance therapy options in recent years, with 3-month a cycle. This paradigm of long-term treatment needs to consider many other factors such as patients' quality of life, convenience, and burden of long-term treatment. Thus, we perform a secondary analysis to find the optimal treatment duration. The median treatment duration of the patients who received bortezomib-based maintenance after induction and consolidation therapy was 12.9 (0.845.1) months. The PFS was improved with the increasing treatment duration $(p<0.001)$. The OS was significantly prolonged in the patients who received $\geq 12$ months of bortezomib-based maintenance than those with maintenance $<12$ months, with the 5 -year OS of 91.9 vs. $51.1 \%(p<0.001)$ (Figure 3A). However, no difference was observed in OS between the patients who received the 12-24 or $\geq 24$ months of bortezomib-based maintenance ( $p=0.292)$, with a 5 -year OS of 96.4 vs $86.6 \%$ (Figure 3B).

The relationship between the maintenance treatment course and the outcome is basically consistent with the above result. The median maintenance cycles were 4 (1-14) of the patients completed after induction and consolidation therapy. The PFS was improved with the increase of the number of the treatment course ( $p<0.001)$, the OS was significantly different in patients with $<4 \mathrm{vs.} \geq 4$ maintenance treatment 
courses ( $p<0.001$ ), with a 5-year OS of 42.3 vs. $92.7 \%$. The OS between patients with $4-9$ vs. $\geq 9$ maintenance treatment courses was not statistically significant ( $p=0.214)$, with a 5-year OS of 95.5 vs. $83.7 \%$.

\section{Discussion}

In the past two decades, with the introduction of new drugs such as proteasome inhibitor bortezomib, and the immunomodulators thalidomide and lenalidomide, the treatment paradigm of NDMM has changed dramatically. Those new drugs have less toxicity than traditional chemotherapy drugs, allows long-term maintenance becoming a treatment paradigm. Maintenance therapy usually refers to administering a course of long-term low-dose chemotherapy after induction and consolidation therapy. In our study, the significance of maintenance treatment not only improved more patients' response (34.3 vs. 13.3\%) but also significantly prolonged the patients' PFS (median PFS: 41.1 vs. 10.5 months) and OS (median OS: not reached vs. 38.6 months). We admit that the PFS was shorter compared with the literature in no maintenance group[8-10]. The reasons are the following: firstly, almost all of our no maintenance patients did not undergo ASCT, moreover, the patient did not receive maintenance partly because their poor physical condition cannot tolerate maintenance. Besides, our limited sample size may impact results. While the survival benefit of maintenance therapy is beyond doubt [8-14].

Various maintenance treatment options in NDMM are recommended within consensus and guidelines[1517]. As the consensus of Mayo Clinic recommends: immunomodulators maintenance is recommended for patients with standard-risk cytogenetics, meanwhile, PI maintenance for high-risk cytogenetics[16]. Data from our center revealed that compared with thalidomide and lenalidomide, the PFS and OS can both benefit from bortezomib-based regimens (median PFS: 43.7 vs. 38.5 months; median OS: not reached vs. 78.5 months), which was consistent with the literature[18]. It is worth noting that in the phase III HOVON-65/GMMG-HD4 trial the early research report showed the OS was superior in bortezomib-based regimens induction and maintenance arm to non-bortezomib-based regimens induction and thalidomide maintenance arm[19], however, after long-term follow-up, the OS was no difference between two arms, due to the majority of patients have relapsed inevitably and received multiple effective post-relapse treatments[20].

To further explore the best maintenance options for patients in different subgroups, we conducted a more detailed subgroup analysis. In younger patients, the OS was more superior in patients with bortezomibbased maintenance (median OS: not reached vs. 78.5 months). Bortezomib does not need dose adjustment for MM patients with renal impairment[21]. Moreover, bortezomib-based regimens before and after autologous stem cell transplantation (ASCT) can overcome the adverse effects of renal damage on prognosis[19, 20, 22]. Our data showed that patients with baseline serum creatinine $<2 \mathrm{mg} / \mathrm{dl}$, both PFS and OS can benefit from bortezomib-based maintenance, whereas, the patients with baseline serum creatinine $\geq 2 \mathrm{mg} / \mathrm{dl}$, no statistical difference was observed between the two maintenance options. It may because most of our patients did not undergo ASCT, the bortezomib-based regimens induction and maintenance treatment without ASCT is not enough to overcome the adverse effects of renal impairment 
on prognosis. Moreover, due to our limited sample size, we need to interpret this conclusion carefully and expand the number of patients to verify the conclusion. The response after induction and consolidation was also an important factor to choose maintenance treatment options, in the patients who achieved only PR after induction and consolidation, the bortezomib-based maintenance significant prolonged the PFS and OS, however, in the patients who achieved at least VGPR, there was no statistical difference in PFS and OS between two groups. Clinal trial research showed that bortezomib consolidation after ASCT only improved the PFS of patients not achieving at least VGPR, no effect on patients who achieved at least VGPR, and did not prolong OS in both category patients[23]. Consolidation therapy refers to utilize a short course of treatment for reducing the number of residual tumor cells, which cloud prolonged the PFS but not OS[18]. Consolidation and maintenance play a different role in patients' outcomes. In high-risk patients (including ISS 2-3, DS 2-3, and RISS 2-3), it's very necessary to choose bortezomib-based maintenance, the PFS and OS were significantly superior to thalidomide or lenalidomide maintenance. Yet, in the non-high-risk patient, the difference did not reach statistical significance between the two groups.

The NCCN guidelines have added bortezomib-based maintenance as an option for patients with or without ASCT[24]. In PI maintenance, the PCD regimen was the most adopted option, due to its greater efficacy, fewer adverse reactions, lower cost, and convenience to use. It is the first-line treatment for NDMM approved by multiple centers in induction therapy [25-27], which is also be widely used in maintenance. The treatment duration usually lasts 2-3 years or until the disease progresses. We performed a secondary analysis to found the optimal treatment duration, the optimal duration that the patient can not only achieve the best disease relief but also reduce the burden of long-term maintenance on the patients. Through our analysis, the bortezomib-based maintenance duration lasting 12-24 months after induction and consolidation therapy can reach a satisfactory $\mathrm{OS}$, the outcome of maintaining more than 24 months is similar to that of $12-24$ months. It is equivalent to $4-8$ courses of maintenance treatment after induction and consolidation treatment, with 3-month a cycle.

The first oral bioavailable PI ixazomib was licensed for the treatment of MM in 2018 in China. Multiple studies have confirmed its effectiveness and safety[28, 29]. Besides, ixazomib has become a category 1 "other recommended" maintenance option for patients eligible for transplantation in NCCN guidelines [24]. Ixazomib may play an important role in the future maintenance paradigm. Various studies are ongoing to explore the best maintenance according to different patient subgroups and optimize individual patient outcomes, at the same time, may be able to provide more different maintenance options. In the future maintenance paradigm not only efficacy and adverse effects be considered, but also the quality of patient life, convenience, compliance of long-term treatment, and financial burden. In addition, the role of minimal residual disease (MRD) in guiding maintenance treatment decisions has been increasing attention. The maintenance paradigm will become increasingly well-established.

\section{Conclusion}


In our study demonstrate the efficacy of bortezomib-based regimens as maintenance. Besides, we have some suggestions of optimal maintenance therapy according to different patient subgroups. And we provide a reference for the optimal maintenance duration in the real world. Due to sample size limitations, we may need to interpret a few conclusions carefully. At the same time, we will continue focusing on maintenance therapy in the future to perform research with larger sample size, longer follow-up, and more maintenance options.

\section{Declarations}

\section{Ethical Approval}

The study was approved by the Ethics Committee of the First Affiliated Hospital of Zhejiang University School of Medicine, with the ethical number of (2020) IIT (822). We got the patient's informed consent and promised that all patients' information was strictly confidential.

\section{Consent for publication}

Not applicable.

\section{Availability of data and materials}

The datasets used and/or analyzed during the current study are available from the corresponding author on reasonable request.

\section{Competing interests}

The authors declare no competing interests

\section{Funding}

This study was supported by the National Natural Science Foundation of China (grant number 81800201), and the Natural Science Foundation of Zhejiang Province (grant number LY17H080001).

\section{Authors' contributions}

Xiaoyan Han and Jingsong He: Contributed to the study design and provide the date.

Chunxiang Jin: Wrote the manuscript and reviewed the literature.

Gaofeng Zheng, Yi Li, Wenjun Wu, Weiyan Zheng, Guoqing Wei and He Huang: Reviewed and wrote part of the manuscript.

Enfan Zhang: Reviewed the manuscript and provided images.

Zhen Cai: Supervised and formulated the manuscript; wrote the manuscript; review of literature. 
None

\section{References}

1. Siegel RL, Miller KD, Jemal A: Cancer statistics, 2020. CA Cancer J Clin 2020, 70(1):7-30.

2. Lahuerta JJ, Paiva B, Vidriales MB, Cordon L, Cedena MT, Puig N, Martinez-Lopez J, Rosinol L, Gutierrez NC, Martin-Ramos ML et al: Depth of Response in Multiple Myeloma: A Pooled Analysis of Three PETHEMA/GEM Clinical Trials. J Clin Oncol 2017, 35(25):2900-2910.

3. Lehners N, Becker N, Benner A, Pritsch M, Lopprich M, Mai EK, Hillengass J, Goldschmidt H, Raab MS: Analysis of long-term survival in multiple myeloma after first-line autologous stem cell transplantation: impact of clinical risk factors and sustained response. Cancer Med 2018, 7(2):307316.

4. San Miguel JF, Schlag R, Khuageva NK, Dimopoulos MA, Shpilberg O, Kropff M, Spicka I, Petrucci MT, Palumbo A, Samoilova OS et al: Bortezomib plus melphalan and prednisone for initial treatment of multiple myeloma. The New England journal of medicine 2008, 359(9):906-917.

5. Durie BGM, Hoering A, Abidi MH, Rajkumar SV, Epstein J, Kahanic SP, Thakuri M, Reu F, Reynolds CM, Sexton $\mathrm{R}$ et al: Bortezomib with lenalidomide and dexamethasone versus lenalidomide and dexamethasone alone in patients with newly diagnosed myeloma without intent for immediate autologous stem-cell transplant (SWOG S0777): a randomised, open-label, phase 3 trial. Lancet 2017, 389(10068):519-527.

6. Attal M, Lauwers-Cances V, Hulin C, Leleu X, Caillot D, Escoffre M, Arnulf B, Macro M, Belhadj K, Garderet $\mathrm{L}$ et al: Lenalidomide, Bortezomib, and Dexamethasone with Transplantation for Myeloma. The New England journal of medicine 2017, 376(14):1311-1320.

7. Kumar S, Paiva B, Anderson KC, Durie B, Landgren O, Moreau P, Munshi N, Lonial S, Bladé J, Mateos $\mathrm{M}-\mathrm{V}$ et al: International Myeloma Working Group consensus criteria for response and minimal residual disease assessment in multiple myeloma. The Lancet Oncology 2016, 17(8):e328-e346.

8. Palumbo A, Bringhen S, Larocca A, Rossi D, Di Raimondo F, Magarotto V, Patriarca F, Levi A, Benevolo G, Vincelli ID et al: Bortezomib-melphalan-prednisone-thalidomide followed by maintenance with bortezomib-thalidomide compared with bortezomib-melphalan-prednisone for initial treatment of multiple myeloma: updated follow-up and improved survival. J Clin Oncol 2014, 32(7):634-640.

9. Attal M, Harousseau JL, Leyvraz S, Doyen C, Hulin C, Benboubker L, Yakoub Agha I, Bourhis JH, Garderet L, Pegourie B et al: Maintenance therapy with thalidomide improves survival in patients with multiple myeloma. Blood 2006, 108(10):3289-3294.

10. Lokhorst HM, van der Holt B, Zweegman S, Vellenga $E$, Croockewit S, van Oers MH, von dem Borne P, Wijermans $\mathrm{P}$, Schaafsma $\mathrm{R}$, de Weerdt $\mathrm{O}$ et al: A randomized phase 3 study on the effect of thalidomide combined with adriamycin, dexamethasone, and high-dose melphalan, followed by thalidomide maintenance in patients with multiple myeloma. Blood 2010, 115(6):1113-1120. 
11. Ludwig H, Zojer N: Fixed duration vs continuous therapy in multiple myeloma. Hematology Am Soc Hematol Educ Program 2017, 2017(1):212-222.

12. Palumbo A, Gay F, Cavallo F, Di Raimondo F, Larocca A, Hardan I, Nagler A, Petrucci MT, Hajek R, Pezzatti S et al: Continuous Therapy Versus Fixed Duration of Therapy in Patients With Newly Diagnosed Multiple Myeloma. J Clin Oncol 2015, 33(30):3459-3466.

13. Kagoya $Y$, Nannya $Y$, Kurokawa M: Thalidomide maintenance therapy for patients with multiple myeloma: meta-analysis. Leuk Res 2012, 36(8):1016-1021.

14. Attal M, Lauwers-Cances V, Marit G, Caillot D, Moreau P, Facon T, Stoppa AM, Hulin C, Benboubker L, Garderet $\mathrm{L}$ et al: Lenalidomide maintenance after stem-cell transplantation for multiple myeloma. The New England journal of medicine 2012, 366(19):1782-1791.

15. Gay F, Engelhardt M, Terpos E, Wasch R, Giaccone L, Auner HW, Caers J, Gramatzki M, van de Donk N, Oliva $S$ et al: From transplant to novel cellular therapies in multiple myeloma: European Myeloma Network guidelines and future perspectives. Haematologica 2018, 103(2):197-211.

16. Gonsalves WI, Buadi FK, Ailawadhi S, Bergsagel PL, Chanan Khan AA, Dingli D, Dispenzieri A, Fonseca R, Hayman SR, Kapoor P et al: Utilization of hematopoietic stem cell transplantation for the treatment of multiple myeloma: a Mayo Stratification of Myeloma and Risk-Adapted Therapy (mSMART) consensus statement. Bone Marrow Transplant 2019, 54(3):353-367.

17. Moreau P, San Miguel J, Sonneveld P, Mateos MV, Zamagni E, Avet-Loiseau H, Hajek R, Dimopoulos MA, Ludwig H, Einsele $\mathrm{H}$ et al: Multiple myeloma: ESMO Clinical Practice Guidelines for diagnosis, treatment and follow-up. Ann Oncol 2017, 28(suppl_4):iv52-iv61.

18. Zhang S, Kulkarni AA, Xu B, Chu H, Kourelis T, Go RS, Wang ML, Bachanova V, Wang Y: Bortezomibbased consolidation or maintenance therapy for multiple myeloma: a meta-analysis. Blood Cancer $\mathrm{J}$ 2020, 10(3):33.

19. Sonneveld P, Schmidt-Wolf IG, van der Holt B, El Jarari L, Bertsch U, Salwender H, Zweegman S, Vellenga $\mathrm{E}$, Broyl A, Blau IW et al: Bortezomib induction and maintenance treatment in patients with newly diagnosed multiple myeloma: results of the randomized phase III HOVON-65/ GMMG-HD4 trial. J Clin Oncol 2012, 30(24):2946-2955.

20. Goldschmidt H, Lokhorst HM, Mai EK, van der Holt B, Blau IW, Zweegman S, Weisel KC, Vellenga E, Pfreundschuh $\mathrm{M}$, Kersten $\mathrm{MJ}$ et al: Bortezomib before and after high-dose therapy in myeloma: longterm results from the phase III HOVON-65/GMMG-HD4 trial. Leukemia 2018, 32(2):383-390.

21. Jagannath S, Barlogie B, Berenson JR, Singhal S, Alexanian R, Srkalovic G, Orlowski RZ, Richardson $\mathrm{PG}$, Anderson J, Nix D et al: Bortezomib in recurrent and/or refractory multiple myeloma. Initial clinical experience in patients with impared renal function. Cancer 2005, 103(6):1195-1200.

22. Scheid C, Sonneveld P, Schmidt-Wolf IG, van der Holt B, el Jarari L, Bertsch U, Salwender H, Zweegman S, Blau IW, Vellenga E et al: Bortezomib before and after autologous stem cell transplantation overcomes the negative prognostic impact of renal impairment in newly diagnosed multiple myeloma: a subgroup analysis from the HOVON-65/GMMG-HD4 trial. Haematologica 2014, 99(1):148-154. 
23. Mellqvist UH, Gimsing P, Hjertner O, Lenhoff S, Laane E, Remes K, Steingrimsdottir H, Abildgaard N, Ahlberg $\mathrm{L}$, Blimark $\mathrm{C}$ et al: Bortezomib consolidation after autologous stem cell transplantation in multiple myeloma: a Nordic Myeloma Study Group randomized phase 3 trial. Blood 2013, 121(23):4647-4654.

24. Kumar SK, Callander NS, Adekola K, Anderson L, Baljevic M, Campagnaro E, Castillo JJ, Chandler JC, Costello C, Efebera Y et al: Multiple Myeloma, Version 3.2021, NCCN Clinical Practice Guidelines in Oncology. Journal of the National Comprehensive Cancer Network : JNCCN2020, 18(12):1685-1717.

25. He J, He D, Han X, Zheng G, Wei G, Zhao Y, Yang Y, Wu W, Fu J, Shou L et al: Bortezomib-Based Regimens for Newly Diagnosed Multiple Myeloma in China: A Report of 12-Year Real-World Data. Front Pharmacol 2020, 11:561601.

26. Ong SY, Ng HY, Surendran S, Linn YC, Chen Y, Goh YT, Diong C, Gopalakrishnan SK: Subcutaneous bortezomib combined with weekly cyclophosphamide and dexamethasone is an efficient and well tolerated regime in newly diagnosed multiple myeloma. Br J Haematol 2015, 169(5):754-756.

27. He J, Yang L, Han X, Zheng G, Zheng W, Wei G, Wu W, Ye X, Shi J, Xie W et al: The choice of regimens based on bortezomib for patients with newly diagnosed multiple myeloma. PLoS One 2014, 9(6):e99174.

28. Dimopoulos MA, Gay F, Schjesvold F, Beksac M, Hajek R, Weisel KC, Goldschmidt H, Maisnar V, Moreau P, Min CK et al: Oral ixazomib maintenance following autologous stem cell transplantation (TOURMALINE-MM3): a double-blind, randomised, placebo-controlled phase 3 trial. Lancet 2019, 393(10168):253-264.

29. Ding K, Yu H, Shao YY, Li LY, Wang CM, Song J, Li LJ, Fu R: Real-world Data on the Efficacy and Safety of Ixazomib-based Therapy in Multiple Myeloma: A Single-center Study in China. Cancer Manag Res 2020, 12:8935-8941.

\section{Tables}

Table 1. Baseline characteristics between NDMM patients with or without maintenance. 


\begin{tabular}{|c|c|c|c|}
\hline & Maintenance & No maintenance & $\mathrm{p}$ \\
\hline & $N=181$ & $N=45$ & \\
\hline Characteristic & $\mathrm{N}(\%)$ & $\mathrm{N}(\%)$ & \\
\hline \multicolumn{4}{|l|}{ Age(years) } \\
\hline Median (range) & $62(39-84)$ & $61(44-77)$ & 0.79 \\
\hline Gender & & & 0.129 \\
\hline Male & $98(54.1)$ & $30(66.7)$ & \\
\hline Female & $83(45.9)$ & 15(33.3) & \\
\hline Type of myeloma & & & 0.445 \\
\hline $\lg A$ & $48(26.5)$ & $12(26.7)$ & \\
\hline $\lg D$ & $11(6.1)$ & $3(6.7)$ & \\
\hline $\lg G$ & $75(41.4)$ & $24(53.3)$ & \\
\hline Light chain & $46(25.4)$ & $6(13.3)$ & \\
\hline Biphenotypic & $1(0.6)$ & $0(0)$ & \\
\hline ISS stage & & & 0.962 \\
\hline 1 & $68(37.6)$ & 16(35.6) & \\
\hline 2 & $56(30.9)$ & 14(31.1) & \\
\hline 3 & $57(31.5)$ & 15(33.3) & \\
\hline $\operatorname{RISS}^{\mathrm{a}}(\mathrm{N}=204)$ & & & 0.199 \\
\hline 1 & $22(13.7)$ & $2(4.7)$ & \\
\hline 2 & 103(64.0) & $28(65.1)$ & \\
\hline 3 & $36(22.4)$ & 13(30.2) & \\
\hline Durie-Salmon stage & & & 0.360 \\
\hline $1 A+1 B$ & $17(9.4)$ & 7(15.6) & \\
\hline $2 A+2 B$ & $22(12.2)$ & 7(15.6) & \\
\hline $3 A+3 B$ & $142(78.5)$ & $31(68.9)$ & \\
\hline ASCT & & & 0.011 \\
\hline Yes & $31(17.1)$ & $1(2.3)$ & \\
\hline No & $150(82.9)$ & $44(97.7)$ & \\
\hline
\end{tabular}




\begin{tabular}{|c|c|c|c|}
\hline Response after ind & & & 0.267 \\
\hline PR & 72(39.8) & $22(48.9)$ & \\
\hline$\geq$ VGPR & $109(60.2)$ & $23(51.1)$ & \\
\hline Induction therapy & & & 0.065 \\
\hline PAD & $27(14.9)$ & $6(13.3)$ & \\
\hline PCD & $122(67.4)$ & $28(62.2)$ & \\
\hline PD & $25(13.8)$ & $4(8.9)$ & \\
\hline PTD & $5(2.8)$ & $5(11.1)$ & \\
\hline VRD & $2(1.1)$ & $2(4.4)$ & \\
\hline
\end{tabular}

Note: ${ }^{a}$ Due to lack of FISH data, 20 patients of the maintenance group and 2 patients of the no maintenance group can't be stratified by RISS staging.

Abbreviations: NDMM, newly diagnosed multiple myeloma; ISS, International Staging System; R-ISS, revised International Staging System; ASCT, autologous hematopoietic stem cell transplantation; PR, partial response; VGPR, very good partial response; PAD, bortezomib, doxorubicin and dexamethasone; PCD, bortezomib, cyclophosphamide and dexamethasone; PD, bortezomib and dexamethasone; PTD, bortezomib, thalidomide and dexamethasone. VRD, bortezomib, lenalidomide and dexamethasone.

Table 2. Baseline characteristics between NDMM patients with proteasome inhibitor or immunomodulators maintenance. 


\begin{tabular}{|c|c|c|c|}
\hline & $\mathrm{PI}$ & IMiDs & $\mathrm{p}$ \\
\hline & $\mathrm{N}=127$ & $N=54$ & \\
\hline Characteristic & N (\%) & $\mathrm{N}(\%)$ & \\
\hline \multicolumn{4}{|l|}{ Age(years) } \\
\hline Median (range) & $62(41-82)$ & $63(39-82)$ & 0.153 \\
\hline$<65$ years & $83(65.4)$ & $30(55.6)$ & 0.213 \\
\hline$\geq 65$ years & $44(34.6)$ & $24(44.4)$ & \\
\hline Gender & & & 0.120 \\
\hline Male & $64(50.4)$ & $34(63.0)$ & \\
\hline Female & $63(49.6)$ & $20(37.0)$ & \\
\hline Type of myeloma & & & 0.219 \\
\hline $\lg A$ & $35(27.6)$ & $13(24.1)$ & \\
\hline $\lg D$ & $8(6.3)$ & $3(5.6)$ & \\
\hline $\lg G$ & $46(36.2)$ & $29(53.7)$ & \\
\hline Light chain & $37(29.1)$ & $9(16.7)$ & \\
\hline Biphenotypic & $1(0.8)$ & $0(0)$ & \\
\hline ISS stage & & & 0.745 \\
\hline 1 & 48(37.8) & $20(37.0)$ & \\
\hline 2 & $41(32.3)$ & $15(27.8)$ & \\
\hline 3 & $38(29.9)$ & 19(35.2) & \\
\hline aRISS stage $(\mathrm{N}=161)$ & & & 0.684 \\
\hline 1 & $14(12.5)$ & $8(16.3)$ & \\
\hline 2 & $74(66.1)$ & $29(59.2)$ & \\
\hline 3 & $24(21.4)$ & $12(24.5)$ & \\
\hline Durie-Salmon stage & & & 0.229 \\
\hline $1 A+1 B$ & $12(9.4)$ & $5(9.3)$ & \\
\hline $2 A+2 B$ & $12(9.4)$ & 10(18.5) & \\
\hline $3 A+3 B$ & 103(81.1) & $39(72.2)$ & \\
\hline Induction therapy & & & 0.069 \\
\hline
\end{tabular}




\begin{tabular}{|llll|}
\hline PAD & $19(15.0)$ & $8(14.8)$ \\
\hline PCD & $85(66.9)$ & $37(68.5)$ & \\
\hline PTD & $21(16.5)$ & $4(7.4)$ & \\
\hline VRD & $1(0.8)$ & $4(7.4)$ & \\
\hline Response after induction & & & 0.134 \\
\hline PR & $1(0.8)$ & $1(1.9)$ & \\
\hline VGPR & $48(37.8)$ & $24(44.4)$ & \\
\hline CR & $22(17.3)$ & $14(25.9)$ & \\
\hline
\end{tabular}

Note: ${ }^{a}$ Due to lack of FISH data, 15 patients 015 patients in the PI subgroup and 5 patients in the IMiDs subgroup can't be stratified by RISS staging.

Abbreviations: PI, proteasome inhibitor; IMiDs, immunomodulators.

Table 3. Subgroup analysis of NDMM patients between PI and IMiDs maintenance 


\begin{tabular}{|c|c|c|c|c|c|c|}
\hline \multirow{2}{*}{$\begin{array}{l}\text { Median Survival(m) } \\
(95 \% \mathrm{Cl})\end{array}$} & \multicolumn{2}{|c|}{ Progression-free survival } & \multirow[t]{2}{*}{$\mathrm{p}$} & \multicolumn{2}{|c|}{ Overall survival } & \multirow[t]{2}{*}{$\mathrm{p}$} \\
\hline & PI & IMiDs & & PI & IMiDs & \\
\hline Age < $65(n=113)$ & $\begin{array}{l}45.7(30.9- \\
60.5)\end{array}$ & $\begin{array}{l}41.8(22.1- \\
61.5)\end{array}$ & 0.205 & NR & $\begin{array}{l}78.5(54.9- \\
102.0)\end{array}$ & 0.032 \\
\hline 3-PFS (5- OS) (\%) & 56.6 & 55.0 & & 81.5 & 66.1 & \\
\hline Age $\geq 65(n=68)$ & $\begin{array}{l}43.7(30.0- \\
57.3)\end{array}$ & $\begin{array}{l}26.5(13.8- \\
39.2)\end{array}$ & 0.115 & NR & NR & 0.511 \\
\hline 3-PFS (5- OS) (\%) & 54.1 & 44.4 & & 61.6 & 62.1 & \\
\hline \multicolumn{7}{|l|}{ Creatinine } \\
\hline$<2 \mathrm{mg} / \mathrm{dl}(\mathrm{N}=153)$ & $\begin{array}{l}43.7(31.5- \\
55.9)\end{array}$ & $\begin{array}{l}38.5(22.2- \\
54.8)\end{array}$ & 0.07 & NR & $\begin{array}{l}\text { 78.5(49.8- } \\
107.1)\end{array}$ & 0.036 \\
\hline 3-PFS (5- OS) (\%) & 58.4 & 52.0 & & 76.8 & 64.9 & \\
\hline$\geq 2 \mathrm{mg} / \mathrm{dl}(\mathrm{N}=28)$ & $\begin{array}{l}31.5(11.4- \\
51.6)\end{array}$ & $\begin{array}{l}17.7(13.5- \\
22.0)\end{array}$ & 0.141 & NR & NR & 0.570 \\
\hline 3-PFS (5- OS) (\%) & 44.9 & 0 & & 70.8 & 66.7 & \\
\hline \multicolumn{7}{|l|}{$\begin{array}{l}\text { Response after } \\
\text { induction }\end{array}$} \\
\hline PR (N= 72) & $\begin{array}{l}34.0(19.0- \\
49.0)\end{array}$ & $\begin{array}{l}17.1(2.7- \\
21.6)\end{array}$ & 0.007 & NR & 47.1 (none) & 0.002 \\
\hline 3-PFS (5- OS) (\%) & 44.8 & 25.0 & & 77.9 & 45.1 & \\
\hline$\geq \operatorname{VGPR}(\mathrm{N}=109)$ & $\begin{array}{l}51.6(36.8- \\
66.4)\end{array}$ & $\begin{array}{l}46.9(35.4- \\
58.4)\end{array}$ & 0.831 & NR & NR & 0.826 \\
\hline 3-PFS (5- OS) (\%) & 62.2 & 70.3 & & 78.9 & 80.5 & \\
\hline \multicolumn{7}{|l|}{ Non-High Risk } \\
\hline ISS1(N= 68) & $\begin{array}{l}39.0(25.6- \\
52.4)\end{array}$ & $\begin{array}{l}51.0(40.9- \\
61.0)\end{array}$ & 0.848 & NR & NR & 0.320 \\
\hline 3-PFS (5- OS) (\%) & 53.8 & 64.6 & & 81.5 & 76.5 & \\
\hline DS $1(\mathrm{~N}=17)$ & $\begin{array}{l}29.6(10.5- \\
48.7)\end{array}$ & NR & 0.901 & NR & NR & 0.637 \\
\hline 3-PFS (5- OS) (\%) & 48.6 & 60.0 & & 88.9 & 100.0 & \\
\hline RISS 1 (N= 22) & $\begin{array}{l}38.9(24.0- \\
53.7)\end{array}$ & $\begin{array}{l}19.7(6.0- \\
33.4)\end{array}$ & 0.107 & NR & $\begin{array}{l}47.2(19.5- \\
74.9)\end{array}$ & 0.057 \\
\hline 3-PFS (5- OS) (\%) & 55.6 & 37.5 & & 73.8 & 50.0 & \\
\hline High Risk & & & & & & \\
\hline
\end{tabular}




\begin{tabular}{|lllllll|} 
ISS 2-3(N= 113) & $\begin{array}{l}43.7(28.9- \\
58.4)\end{array}$ & $\begin{array}{l}26.5(11.7- \\
41.4)\end{array}$ & 0.002 & NR & $\begin{array}{l}64.0(41.6- \\
86.4)\end{array}$ & 0.059 \\
\hline 3-PFS (5- OS) (\%) & 57.0 & 40.3 & & 71.4 & 55.2 & \\
\hline DS 2-3(N= 164) & $\begin{array}{l}45.7(34.2- \\
57.2)\end{array}$ & $\begin{array}{l}33.1(16.1- \\
50.0)\end{array}$ & 0.02 & NR & $\begin{array}{l}78.5(52.3- \\
104.6)\end{array}$ & 0.047 \\
\hline 3-PFS (5- OS) (\%) & 56.5 & 49.5 & & 73.9 & 62.9 & \\
\hline RISS 2-3(N= 139) & $\begin{array}{l}39.0(29.6- \\
48.5)\end{array}$ & $\begin{array}{ll}33.1(15.8- \\
50.4)\end{array}$ & 0.06 & NR & $78.5(51.8-$ & 0.044 \\
\hline 3-PFS (5- OS) (\%) & 52.4 & 48.6 & & 75.6 & 62.6 & \\
\hline
\end{tabular}

Abbreviations: m, months; 3-PFS, 3 years of PFS; 5-OS, 5 years of OS; NR, not reached.

Table 4. Adverse reactions analysis between PI and IMiDs maintenance.

\begin{tabular}{|llll|}
\hline Adverse events, $\mathrm{n}(\%)$ & $\mathrm{PI}$ & IMiDs & $\mathrm{p}$ \\
\hline Hematologic events (3/4 grade) & & & \\
\hline Thrombocytopenia & $7(5.5 \%)$ & $4(7.4 \%)$ & 0.625 \\
\hline Neutropenia & $6(4.7 \%)$ & $2(3.7 \%)$ & 0.760 \\
\hline Anemia & $1(0.8 \%)$ & $2(3.7 \%)$ & 0.160 \\
\hline Non-hematologic events (all grades) & & & \\
\hline Peripheral neuropathy & $29(23.0 \%)$ & $18(33.3 \%)$ & 0.149 \\
\hline infection & $28(22.0 \%)$ & $14(25.9 \%)$ & 0.572 \\
\hline Fatigue & $16(12.6 \%)$ & $10(18.5 \%)$ & 0.299 \\
\hline Herpes zoster & $9(7.1 \%)$ & $3(5.6 \%)$ & 0.705 \\
\hline Constipation & $6(4.7 \%)$ & $6(11.1 \%)$ & 0.114 \\
\hline Diarrhea & $5(3.9 \%)$ & $3(3.2 \%)$ & 0.628 \\
\hline Second primary malignancies & $0(0 \%)$ & $2(3.7 \%)$ & 0.029 \\
\hline
\end{tabular}

\section{Figures}




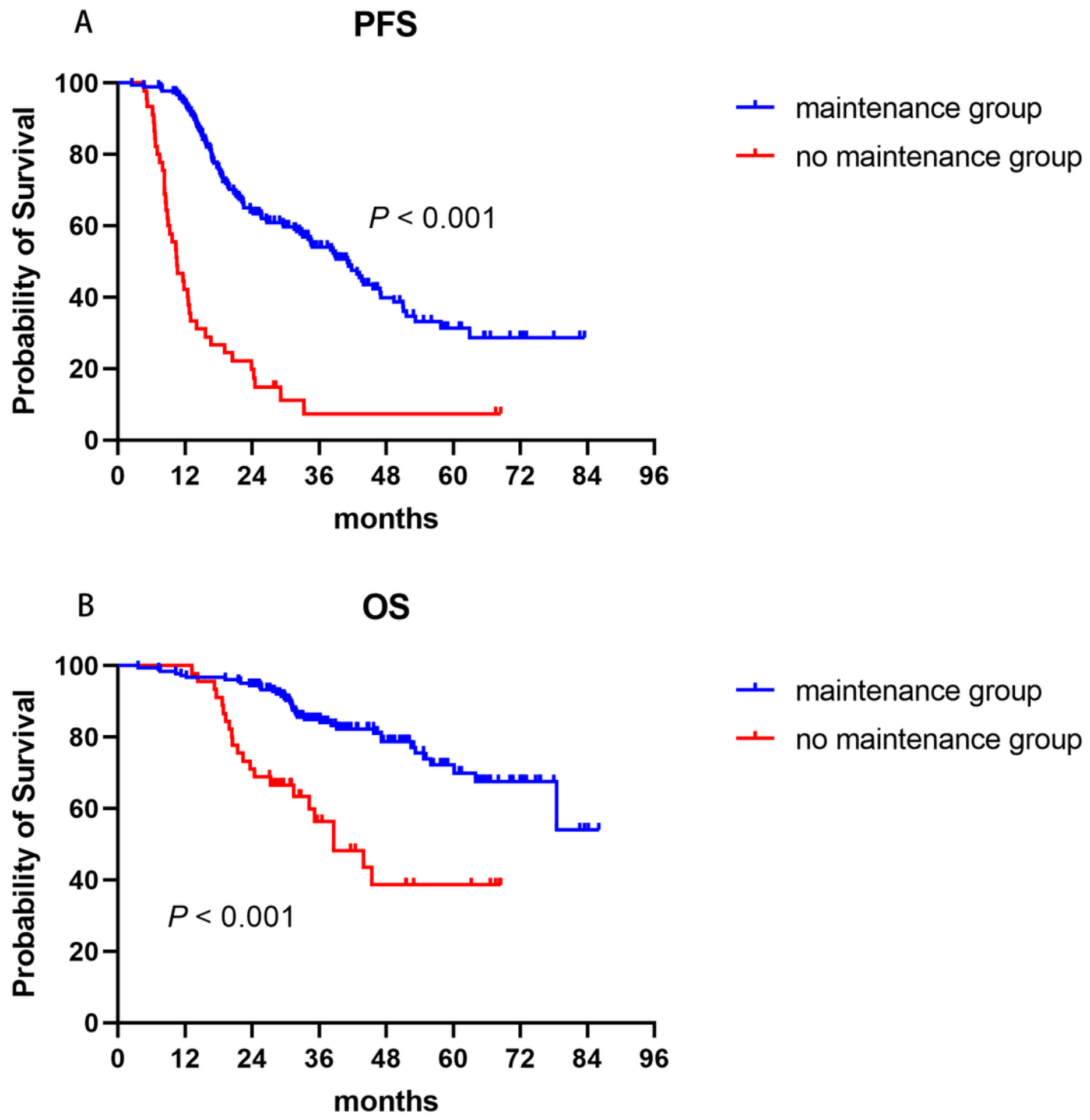

Figure 1

Progression-free (PFS) and overall survival (OS) in NDMM patients with or without maintenance. KaplanMeier curves are shown for (A) PFS and (B) OS. 


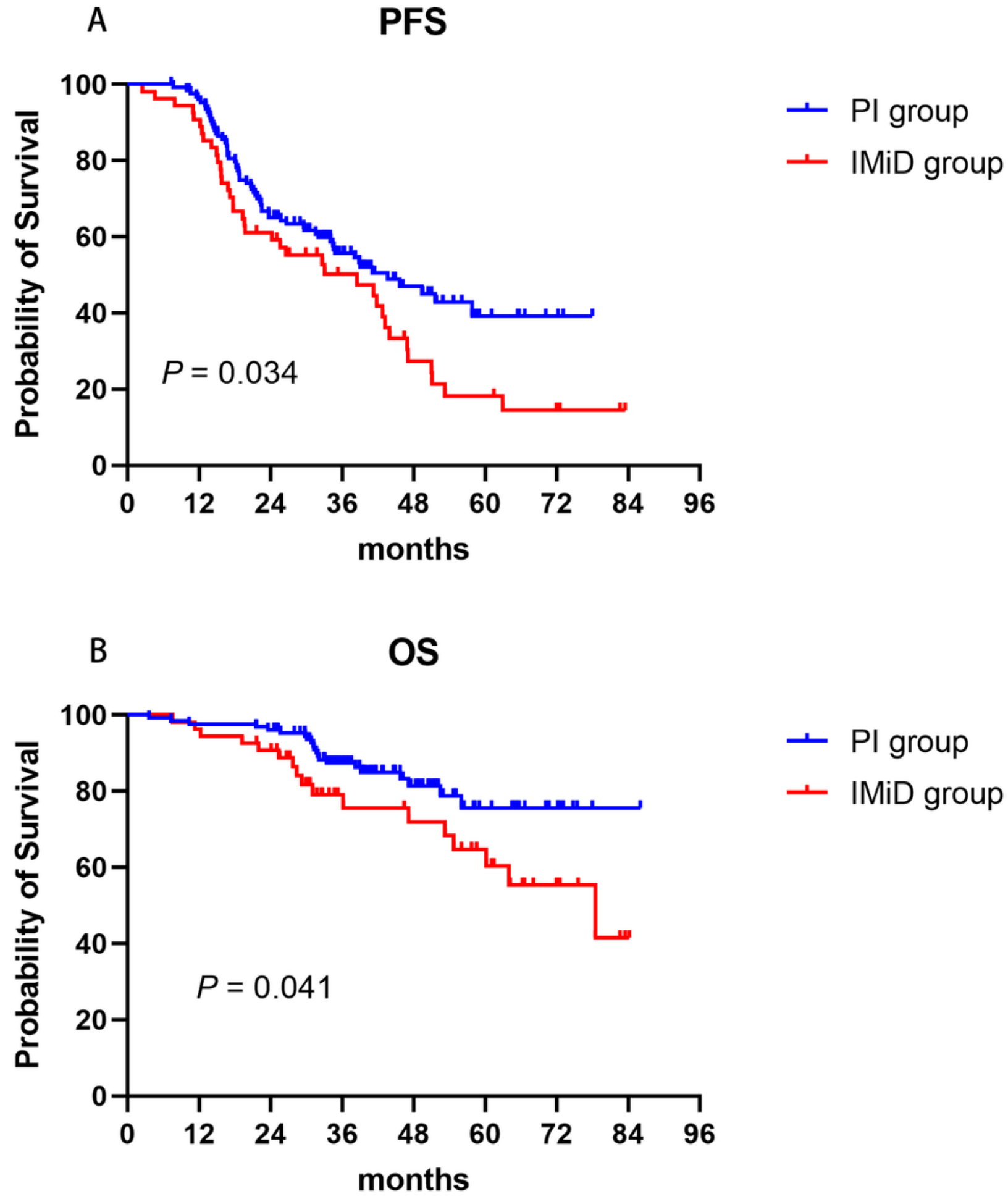

Figure 2

Progression-free (PFS) and overall survival (OS) in NDMM patients with PI or IMiDs maintenance. Kaplan-Meier curves are shown for (A) PFS and (B) OS. PI, proteasome inhibitor; IMiDs, immunomodulators. 

A
OS

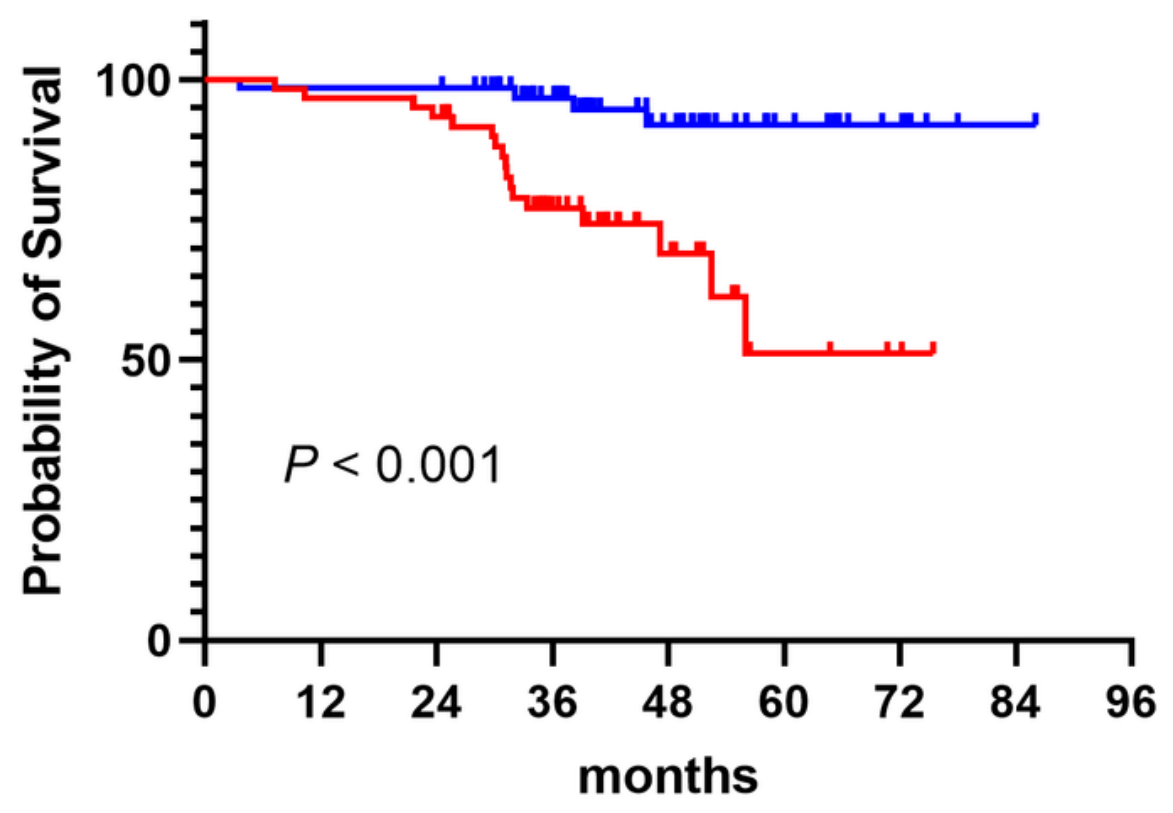

$$
\begin{aligned}
& ->12 \text { months } \\
& ->=12 \text { months }
\end{aligned}
$$

B

OS

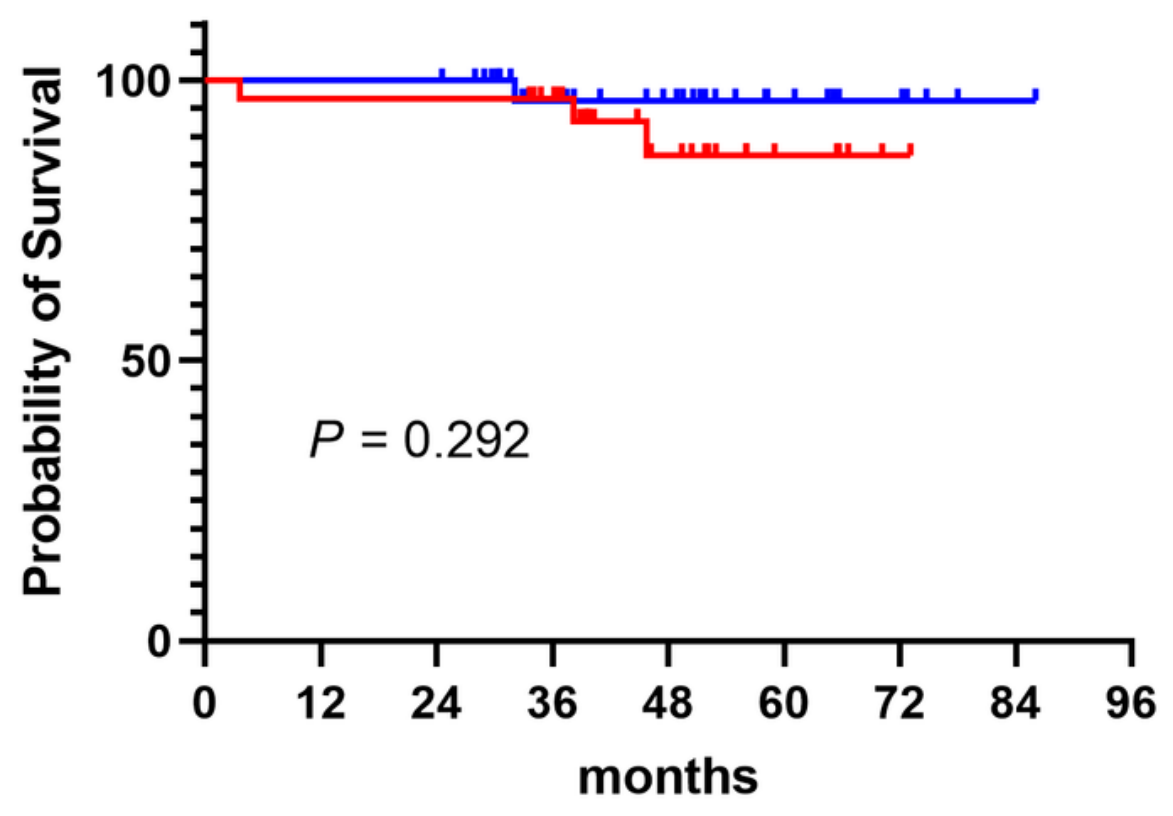

- >= 24 months

- 12-24 months

Figure 3

Overall survival (OS) in NDMM patients with PI maintenance between different treatment duration. Kaplan-Meier curves are shown for (A) patients who received $\geq 12$ months of bortezomib-based maintenance versus those with maintenance $<12$ months; (B) patients who received 12-24 months of bortezomib-based maintenance versus those with maintenance $\geq 24$ months. 